\title{
THE NSW HEALTH BREASTFEEDING PROJECT
}

\section{Edwina Macoun}

Nutrition and Physical Activity Branch NSW Health Department

The NSW Health Breastfeeding Project was set up in 2003 as a result of a growing emphasis in government policy on the importance of increasing breastfeeding rates. Encouraging more women to breastfeed their babies and to do so for longer are goals of Eat well NSW: strategic directions for public health nutrition 2003-2007 and of The prevention of obesity in children and young people: NSW Government Action Plan 2003-2007. ${ }^{1}$ A commitment to support and promote breastfeeding is also congruent with NSW Health's commitment to equity, as mothers who are young, single, indigenous, living in poorer areas, without post school qualifications or born in countries other than Australia, Oceania, Europe or America are less likely to breastfeed. ${ }^{2}$ In response to these goals, the Nutrition and Physical Activity Branch of NSW Health is leading the NSW Health Breastfeeding Project over three years (2003-2006) and working in close consultation with health sector stakeholders.

The aim of the NSW Health Breastfeeding Project is to contribute to an environment that enables mothers, families and other caregivers to make informed choices about the most appropriate feeding practices for infants. In recognition of the substantial role of the health sector in infant feeding decisions, the project seeks to increase organisational commitment and action within the NSW Health system for the protection, promotion and support of breastfeeding as a public health issue. The project also aims to encourage the application of evidence-based practices to promote and support breastfeeding, and to ensure a focus on breastfeeding services that reach disadvantaged and at-risk groups. ${ }^{3}$ The project will foster the dissemination of practices, activities and service models shown to be effective, such as the Baby Friendly Hospital Initiative ${ }^{4}$ (described in the article by Heads in this issue).

One of the main activities of the project is to develop an explicit NSW Health breastfeeding policy. The policy will direct action in those areas of health service provision that can positively influence mothers' breastfeeding practices. Other activities will involve professional development and the preparation and dissemination of breastfeeding resources to support policy implementation.

The NSW Breastfeeding Project Steering Committee, representing stakeholders in the health sector, was established in the initial stage of the project. The committee has refined the scope of the project and will provide advice and recommendations on policy development and implementation. Groups represented include the NSW Midwives Association, NSW Lactation College, Child and Family Health Nurses Association, Australian Lactation Consultants Association, Australian Breastfeeding Association (NSW Branch), Dietitians Association of Australia (NSW Branch), Aboriginal Health and Medical Research Council, NSW Centre for Public Health Nutrition, Pharmacy Guild of Australia (NSW Branch) and the Multicultural Health Communications Service. Branches of the NSW Department of Health and professional networks within NSW Health are also represented. The project coordinator is based at the NSW Centre for Public Health Nutrition.

The second stage of the project involved broad consultation with specialist managers, service providers and professional and community bodies to assess the feasibility of implementing proposed evidence-based practices and interventions. The third stage of the project will involve finalisation of the policy, establishment of baseline data for policy monitoring purposes and active dissemination of the policy and support materials.

\section{REFERENCES}

1. NSW Department of Health. Prevention of obesity in children and young people. NSW Government action plan 2003-2007. Sydney: NSW Department of Health, 2003. At www.health. nsw.gov.au/obesity/adult/gap/ObesityActionPlan.pdf, accessed 8 June 2005.

2. NSW Health. In all fairness: increasing equity in health across New South Wales. Sydney: NSW Department of Health, 2004. At www.health.nsw.gov.au/pubs/2004/pdf/fairnessreport.pdf, accessed 8 June 2005.

3. Hector D, King L, Webb K. Overview of recent reviews of interventions to promote and support breastfeeding. Sydney: NSW Centre for Public Health Nutrition, 2004.

4. World Health Organization. Evidence for the ten steps to successful breastfeeding. Geneva: WHO/CHD/98.9 Division of Child Health and Development; 1998. Available at www. who.int/reproductive-health/docs/breastfeeding.pdf. 